\title{
Methylation status as a predictor of intravesical Bacillus Calmette-Guérin (BCG) immunotherapy response of high grade non-muscle invasive bladder tumor
}

\author{
Petr Husek ${ }^{\mathrm{a}}$, Jaroslav Pacovsky ${ }^{\mathrm{a}}$, Marcela Chmelarova ${ }^{\mathrm{b}}$, Miroslav Podhola ${ }^{\mathrm{c}}$, Milos Brodak ${ }^{\mathrm{a}}$
}

Background and Aims. Genetic and epigenetic alterations play an important role in urothelial cancer pathogenesis. Deeper understanding of these processes could help us achieve better diagnosis and management of this life-threatening disease. The aim of this research was to evaluate the methylation status of selected tumor suppressor genes for predicting BCG response in patients with high grade non-muscle-invasive bladder tumor (NMIBC).

Materials and Methods. We retrospectively evaluated 82 patients with high grade non-muscle-invasive bladder tumor (stage Ta, T1, CIS) who had undergone BCG instillation therapy. We compared epigenetic methylation status in BCGresponsive and BCG-failure groups. We used the MS-MLPA (Methylation-Specific Multiplex Ligation-Dependent Probe Amplification probe sets ME001 and ME004. The control group was 13 specimens of normal urotel (bladder tissue)). Results. Newly identified methylations in high grade NMIBC were found in MUS81a, NTRK1 and PCCA. The methylation status of $C D K N 2 B\left(P=0.00312^{* *}\right)$ and MUS81a $\left(P=0.0191^{*}\right)$ is associated with clinical outcomes of BCG instillation therapy response. CDKN2B and MUS81a unmethylation was found in BCG failure patients.

Conclusion. The results show that the methylation status of selected tumor suppressor genes (TSGs) has the potential for predicting BCG response in patients with NMIBC high grade tumors. Tumor suppressor genes such as CDKN2b, MUS81a, PFM-1, MSH6 and THBS1 are very promising for future research.

Key words: BCG, bladder cancer, CDKN2b, methylation

Received: June 27, 2016; Accepted with revision: March 13, 2017; Available online: March 22, 2017

https://doi.org/10.5507/bp.2017.008

${ }^{a}$ Department of Urology, Faculty of Medicine in Hradec Kralove, Charles University in Prague and University Hospital in Hradec Kralove, Czech Republic

bInstitute of Clinical Biochemistry and Diagnostics, Faculty of Medicine in Hradec Kralove, Charles University in Prague and University Hospital in Hradec Kralove, Czech Republic

'The Fingerland Department of Pathology, Faculty of Medicine in Hradec Kralove, Charles University in Prague and University Hospital in Hradec Kralove, Czech Republic

Corresponding author: Petr Husek, e-mail: petr.husek@fnhk.cz

\section{INTRODUCTION}

Bladder Cancer (BC) is the second most common malignancy of the urinary tract and the seventh most common cancer in men and the $17^{\text {th }}$ in women ${ }^{1}$. BC is nearly three times more common in men that in women ${ }^{2}$. The median age at the time of diagnosis is around 70 years for each gender. BC has two categories. Approximately $75 \%$ of patients with BC present with disease confined to the mucosa or submucosa (non muscle invasive bladder tumor - NMIBC). Carcinoma in situ (CIS) is a very specific subgroup of NMIBC, because it is not a papillary lesion but a flat tumor, which is why CIS can be missed in cystoscopy ${ }^{3}$. CIS is always a high grade tumor. Without any treatment, approximately $54 \%$ of patients with CIS progressed to muscle-invasive or metastatic disease ${ }^{4}$.

The second category covers patients with muscle-invasive $\mathrm{BC}$ (MIBC). These patients have a higher prevalence of progression rates and higher cancer-specific mortality ${ }^{5}$. Patients with NMIBC are indicated to transurethral tumor resection (TUR) alone or with adjuvant treatment (intravesical chemotherapy or intravesical Bacillus CalmetteGuérin (BCG) immunotherapy). Indication for adjuvant therapy is determined in the European Association of Urology Guidelines (Guidelines on NMIBC).

BCG is an attenuated mycobacterium developed as a vaccine for tuberculosis that has demonstrated antitumor activity in $\mathrm{BC}$ intravesical instillation, and significantly reduces the progression risk of high grade papillary lesion and CIS.

The pathologic characteristics and tumor grade are very important. From the standpoint of genetic development, biological behavior, and management, high grade and low grade cancers may be regarded as essentially separate diseases ${ }^{6}$. The therapy of MIBC is radical cystectomy - hard mutilating surgery with urinary diversion. This procedure has significant impact on the quality of the patient's life.

Patients with superficial (NMIBC) high grade tumor and CIS are the focus of our interest. It is a borderline subgroup, where radical and non-radical treatment are both possible. Non-radical therapy means complete tumor resection with adjuvant intravesical immunotherapy (BCG vaccine).

Radical therapy means radical cystectomy. At present we have no markers which would be helpful in deciding 
optimal therapy. Weighing the risk of failure of non-radical treatment against overtreatment by radical therapy constantly presents a dilemma.

The etiology of BC is multifactorial, driven by the multistep accumulation of environmental, genetic and epigenetic factors. Epigenetic analyses include DNA methylation, microRNAs, and histone modification. Methylation status differences were evaluated in our study subgroups.

DNA methylation is a covalent chemical modification by addition of a methyl group at the carbon-5 position of the cytosine ring. Most cytosine methylation occurs in the sequence context 5'-CG-3'. Methylation is mediated by the DNA cytosine methyltransferases. Changed methylation in the transcribed region has a variable effect on gene expression. A new model for the mechanism of carcinogenesis has been proposed in which hypermethylation of unmethylated cytosine-phosphate-guanine $(\mathrm{CpG})$ islands in the promoter regions of tumor suppressor genes (TSG) in normal cells silence these genes and this leads to the cells becoming cancerous ${ }^{7,8}$.

\section{METHODS}

\section{Patients}

We retrospectively evaluated 82 patients with high grade NMIBC (stage Ta, T1, CIS) who had undergone BCG instillation therapy in our urology department. Patients were divided to two groups: BCG response and BCG failure. BCG response we defined as absence of recurrence of, progression of, or death from the disease during follow-up. Our conditions were: complete deep TUR with the presence of detrusor muscle in the specimen; no previous intravesical therapy; complete 6-weekly induction of BCG instillation therapy followed by maintenance BCG therapy just 12 months in patients in this study. BCG therapy was terminated in cases of failure. Schedules of maintenance therapy are unclear in general. Our local schedule covers three weekly doses every three months if there in no reccurence according to cystoscopy. Minimal follow up was 2 years. These conditions were satisfied in 66 patients. Patients' tumor tissues were retrieved from the pathology archive and prepared for DNA isolation and methylation analysis.

The control group comprised 13 specimens of normal urotel (bladder tissue) obtained during cystectomy for benign (fistulas) or malignant (tumor) diagnosis.

The study was approved by the Ethics Committee of the University Hospital Hradec Kralove.

\section{Tumor samples}

Formalin-fixed and paraffin-embedded (FFPE) samples of bladder cancer were retrieved from the archive of the department of pathology. All slides were reviewed by a pathologist.

\section{Control samples}

Normal urothelium was exfoliated from the urinary bladder wall specimen. The inclusion condition was nor- mal urothelium macroscopically and microscopically evaluated by an experienced pathologist. Only one third specimens could be used for analysis according to these strict criteria. Informed consent for bladder tissue manipulation was obtained before surgery. Control samples were harvested from healthy urothelium according to the strict rules of the Local Ethics Committee which is why the group is limited.

\section{DNA isolation}

DNA was extracted from FFPE samples using a Qiagen DNA extraction kit (Hilden, Germany) according to the manufacturer's protocol with minimum modification. The procedure consists of 6 steps: 1. Removing paraffin: paraffin is removed by dissolving out with xylene; 2. Lysis: the sample is lysed under denaturing conditions with proteinase $\mathrm{K}\left(56^{\circ} \mathrm{C}\right.$, overnight); 3 . Heating: 10 min incubation at $70{ }^{\circ} \mathrm{C}$ reverses formalin crosslinking; 4. Binding: DNA bids to the membrane and contaminants flow through; 5.Washing: residual contaminants are washed away; 6. Elution: pure, concentrated DNA is eluted from the membrane. The concentration of isolated DNA was measured by two techniques: fluorimetric (Qubit, Invitrogen) and spectrophotometric (Nanodrop ND - 1000, Thermo Fisher Scientific).

\section{Methylation-Specific Multiplex Ligation-Dependent Probe Amplification (MS-MLPA)}

The present study used the MS-MLPA probe sets ME001 and ME004, which can simultaneously check for aberrant methylation in several tumor suppressor genes (Tables 1, 2). Probe sequences, gene loci and chromosome locations can be found at http://www.mlpa.com. Individual genes were evaluated by two probes, which recognized different Hhal restriction sites in their regions. The experimental procedure was carried out according to the manufacturer's instructions, with minor modifications.

In short, DNA (100 ng) was dissolved up to $5 \mu \mathrm{L}$ in TE-buffer (10 mM Tris.Cl; 0.5 mM EDTA; pH 9.0), denatured and subsequently cooled down to $25^{\circ} \mathrm{C}$. After adding the probe mix, the probes were allowed to hybridize (overnight at $60{ }^{\circ} \mathrm{C}$ ). Subsequently, the samples were divided into two: in one half, the samples were directly ligated, while for the other half ligation was combined with the HhaI digestion enzyme. This digestion resulted in ligation of the methylated sequences only. PCR was performed on all the samples using a standard thermal cycler (GeneAmp 9700, Applied Biosystems), with 35 cycles of denaturation at $95^{\circ} \mathrm{C}$ for $30 \mathrm{~s}$, annealing at $60{ }^{\circ} \mathrm{C}$ for $30 \mathrm{~s}$ and extension at $72{ }^{\circ} \mathrm{C}$ for $1 \mathrm{~min}$. with a final extension of $20 \mathrm{~min}$ at $72 \mathrm{C}$. Aliquots of $0.6 \mu \mathrm{L}$ of the PCR reaction were combined with $0.2 \mu \mathrm{L}$ LIZ-labeled internal size standard (Applied Biosystems, Foster City, CA, USA), and $9.0 \mu \mathrm{L}$ deionized formamide. After denaturation, fragments were separated and quantified by electrophoresis on an ABI 3130 capillary sequencer and analyzed using GeneMapper4.0 (both Applied Biosystems). Peak identification, and values corresponding to peak size in base pairs (bp) and peak areas, were used for further data 
Table 1. Genes in the methylation-specific multiplex ligation-dependent probe amplification (MS-MLPA) KIT ME001 Tumor suppressor (MRC Holland).

\begin{tabular}{|c|c|c|c|}
\hline Gene & Name & Probes & Chromosomal location \\
\hline TIMP3 & TIMP metallopeptidase inhibitor 3 & 02255-L03752 & $22 \mathrm{q} 12.3$ \\
\hline APC & Adenomatous polyposis coli & 01905-L01968 & $5 \mathrm{q} 22.2$ \\
\hline CDKN2A & Cyclin-dependent kinase inhibitor $2 \mathrm{~A}$ & 01524-L01744 & $9 \mathrm{p} 21.3$ \\
\hline MLH1 (a) & MutL homolog 1 & 01686-L01266 & $3 \mathrm{p} 22.2$ \\
\hline ATM & Ataxia telangiectasia mutated & 04044-L03849 & $11 \mathrm{q} 22.3$ \\
\hline RARB & Retinoic acid receptor, beta & 04040-L01698 & $3 \mathrm{p} 24.2$ \\
\hline CDKN2B & Cyclin-dependent kinase inhibitor $2 \mathrm{~B}$ & 00607-L00591 & $9 \mathrm{p} 21.3$ \\
\hline HIC1 & Hypermethylated in cancer 1 & 03804-L00949 & $17 \mathrm{p} 13.3$ \\
\hline CHFR & $\begin{array}{l}\text { Checkpoint with forkhead and ring finger domains, } \\
\text { E3 ubiquitin protein ligase }\end{array}$ & 03813-L03753 & $12 \mathrm{q} 24.33$ \\
\hline BRCA1 & Breast cancer 1 & 05162-L04543 & $17 \mathrm{q} 21.31$ \\
\hline CASP8 & Caspase 8, apoptosis-related cysteine peptidase & 02761-L02210 & $2 \mathrm{q} 33.1$ \\
\hline CDKN1B & Cyclin-dependent kinase inhibitor 1B & 07949-L07730 & $12 \mathrm{p} 13.1$ \\
\hline KLLN & Killin, p53-regulated DNA replication inhibitor & 02203-L08261 & $10 \mathrm{q} 23.3$ \\
\hline BRCA2 & Breast cancer 2 & 04042-L03755 & $13 \mathrm{q} 12.3$ \\
\hline CD44 & CD44 molecule (Indian blood group) & 03817-L01731 & $11 \mathrm{p} 13$ \\
\hline RASSF1 (a) & $\begin{array}{l}\text { Ras association (RalGDS/AF-6) domain family } \\
\text { member } 1\end{array}$ & 02248-L01734 & $3 \mathrm{p} 21.31$ \\
\hline DAPK1 & Death-associated protein kinase 1 & 01677-L01257 & $9 q 21.33$ \\
\hline VHL & Von Hippel-Lindau tumor suppressor & 03810-L01211 & $3 \mathrm{p} 25.3$ \\
\hline ESR1 & Estrogen receptor 1 & 02202-L01700 & $6 \mathrm{q} 25.1$ \\
\hline RASSF1 (b) & $\begin{array}{l}\text { Ras association (RalGDS/AF-6) domain family } \\
\text { member } 1\end{array}$ & 03807-L02159 & $3 \mathrm{p} 21.31$ \\
\hline TP73 & Tumor protein $\mathrm{p} 73$ & 04050-L01263 & $1 \mathrm{p} 36.32$ \\
\hline FHIT & Fragile histidine triad & 02201-L01699 & $3 \mathrm{p} 14.2$ \\
\hline IGSF4 & Cell adhesion molecule 1 & 03819-L03848 & $11 \mathrm{q} 23.3$ \\
\hline CDH13 & Cadherin 13, H-cadherin & 07946-L07727 & $16 \mathrm{q} 23.3$ \\
\hline GSTP1 & Glutathione S-transferase pi 1 & 01638-L01176 & $11 \mathrm{q} 13.2$ \\
\hline MLH1 (b) & MutL homolog 1 & 02260-L01747 & $3 \mathrm{p} 22.2$ \\
\hline
\end{tabular}

processing. Methylation dosage ratio was obtained by the following calculation: $\mathrm{Dm}=\left(\mathrm{P}_{\mathrm{x}} / \mathrm{P}_{\text {ctrl }}\right) \mathrm{Dig} /\left(\mathrm{P}_{\mathrm{x}} / \mathrm{P}_{\text {ctrl }}\right)$ Undig, where Dm is the methylation dosage ratio, $\mathrm{P}_{\mathrm{x}}$ is the peak area of a given probe, $\mathrm{P}_{\text {ctrl }}$ is the sum of the peak areas of all control probes, Dig stands for HhaI digested sample and Undig for undigested sample. Dm can vary between 0 and 1.0 (corresponding to $0-100 \%$ of methylated DNA). Based on previous experiments, we considered a promoter to show methylation if the methylation dosage ratio was $\geq 0.10$, which corresponds to $20 \%$ of methylated DNA (ref. ${ }^{9,10}$ ).

$\mathrm{CpG}$ universal methylated and unmethylated DNA (Zymoresearch, Irvine, CA, USA) were used in every run as controls.

\section{Statistical analysis}

We used the nonparametric Mann-Whitney test for evaluation of differences in age and scores. Fisher's exact two proportions test was used for differences in genes. Associations with $P$-value $<0.05$ were considered to be significant. We used Bonferroni modification of significance level.

\section{RESULTS}

\section{Demographic and clinical characteristics}

We evaluated 66 patients. BCG response was demonstrated by 45 patients (68\%), and BCG failure by 21 patients $(32 \%)$. There was recurrence in 15 patients $(23 \%)$ and progression in $6(9 \%) .3$ patients (5\%) died due to bladder cancer. Average time to BCG therapy failure was 10 months.

Both patient groups and the control group were homogeneous without statistically significant variation. We evaluated age, gender, tumor size, smoking, CIS presence, recurrence and progression score in time resection (Table 3). There was no statistically relevant difference in gender, tumor size, CIS presence or smoking between the two BCG groups. The recurrence score was higher in the BCG failure group in time TUR $(P=0.0109)$. The progression score was not statistically different between the BCG groups $(P=0.188)$.

\section{Methylation results}

Methylation analysis (complete or partial) was performed on 57 patients with cancer and 13 control patients. DNA isolation was unsuccessful in 9 patients, and 
Table 2. Genes in the methylation-specific multiplex ligation-dependent probe amplification (MS-MLPA) KIT ME004 probemix (MRC Holland).

\begin{tabular}{|c|c|c|c|}
\hline Gene & Name & Probes & Chromosomal location \\
\hline EPHB2 & Ephrin receptor B2 & 07910-L07623 & $1 \mathrm{p} 36.1$ \\
\hline BCL2 & B-cell CLL/lymphoma 2 & 10344-L10882 & $18 \mathrm{q} 21.3$ \\
\hline PTEN & Phosphatase and tensin homolog & 10345-L11988 & $10 \mathrm{q} 23.3$ \\
\hline NF1 (a) & Neurofibromin 1 & 03845-L03318 & $17 q 11.2$ \\
\hline RARRES1 & Retinoic acid receptor responder (tazarotene induced) 1 & 03308-L13245 & $3 q 25$ \\
\hline TERT & Telomerase reverse transcriptase & 10346-L10884 & $5 \mathrm{p} 15.3$ \\
\hline THBS1 & Thrombospondin 1 & 02739-L02166 & $15 q 15$ \\
\hline SFRP1 (a) & Secreted frizzled-related protein 1 & 10564-L13246 & $8 \mathrm{p} 11.2$ \\
\hline IGF2R (a) & Insulin-like growth factor 2 receptor & 02800-L02185 & $6 q 26$ \\
\hline NF1 (b) & Neurofibromin 1 & 03844-L03317 & $17 \mathrm{q} 11.2$ \\
\hline TWIST1 & Twist homolog 1 & 07015-L06626 & $7 \mathrm{p} 21.2$ \\
\hline APAF1 (a) & Apoptotic peptidase activating factor 1 & 09165-L09458 & $12 \mathrm{q} 23.1$ \\
\hline PCNA & Proliferating cell nuclear antigen & 03955-L03394 & $20 \mathrm{p} 12.3$ \\
\hline DNAJC15 & DnaJ (Hsp40) homolog, subfamily C, member 15 & 03297-L02661 & $13 \mathrm{q} 14.1$ \\
\hline NTRK1 & Neurotrophic tyrosine kinase, receptor, type 1 & 03970-L03357 & $1 \mathrm{q} 23.1$ \\
\hline PXMP4 (a) & Peroxisomal membrane protein 4 & 03303-L13247 & $20 \mathrm{q} 11.2$ \\
\hline MEN1 (a) & Multiple endocrine neoplasia I & 09168-L09461 & $11 \mathrm{q} 13.1$ \\
\hline LMNA & Lamin $\mathrm{A} / \mathrm{C}$ & 12287-L13799 & $1 \mathrm{q} 22$ \\
\hline APAF1 (b) & Apoptotic peptidase activating factor 1 & 09166-L09459 & $12 \mathrm{q} 23.1$ \\
\hline PCCA & Propionyl CoA carboxylase, alpha polypeptide & 08676-L08688 & $13 q 32.3$ \\
\hline PAX6 & Paired box 6 & 03748-L03208 & $11 \mathrm{p} 13$ \\
\hline RBM14 & RNA binding motif protein 14 & 09429-L09678 & $11 \mathrm{q} 13$ \\
\hline MUS81 (a) & MUS81 endonuclease homolog & 09157-L09315 & $11 q 13.1$ \\
\hline IGF2R (b) & Insulin-like growth factor 2 receptor & 02801-L02186 & $6 \mathrm{q} 26$ \\
\hline SFRP1 (b) & Secreted frizzled-related protein 1 & 10563-L11109 & $8 \mathrm{p} 11.2$ \\
\hline GATA4 & GATA binding protein 4 & 03754-L13255 & $8 \mathrm{p} 23.1$ \\
\hline PXMP4 (b) & Peroxisomal membrane protein 4 & 03304-L13248 & $20 \mathrm{q} 11.2$ \\
\hline MEN1 (b) & Multiple endocrine neoplasia I & 09167-L09460 & $11 \mathrm{q} 13.1$ \\
\hline MUS81 (b) & MUS81 endonuclease homolog & 10574-L09314 & $11 \mathrm{q} 13.1$ \\
\hline WIF1 & WNT inhibitory factor 1 & 10361-L10899 & $12 \mathrm{q} 14.3$ \\
\hline $\mathrm{CDH} 1$ & Cadherin 1, type 1, E-cadherin (epithelial) & 10364-L13254 & $16 \mathrm{q} 22.1$ \\
\hline
\end{tabular}

Table 3. Demographic characteristics of the subgroups.

\begin{tabular}{|c|c|c|c|c|c|}
\hline Characteristic & $\begin{array}{c}\text { BCG failure } \\
(\mathrm{n}=16)\end{array}$ & $\begin{array}{c}\text { BCG response } \\
(n=41)\end{array}$ & $\begin{array}{c}\text { controls } \\
(n=13)\end{array}$ & $P^{1}$ & $P^{2}$ \\
\hline Age [years, median (range)] & $68(51-79)$ & $67(42-84)$ & $67(60-73)$ & 0.903 & 0.901 \\
\hline Smoking [number $(\%)]$ & $8(50 \%)$ & $30(73 \%)$ & $11(85 \%)$ & 0.325 & 0.0619 \\
\hline Male gender [number $(\%)]$ & $13(81 \%)$ & $34(83 \%)$ & $11(85 \%)$ & 1.00 & 1.00 \\
\hline Size of tumor more that $3 \mathrm{~cm}$ [number (\%)] & $7(44 \%)$ & $22(54 \%)$ & - & - & 0.770 \\
\hline Recurrence score [median (range)] & $10(6-13)$ & $8(2-12)$ & - & - & 0.0109 \\
\hline Progression score [median (range)] & $14(10-20)$ & $12(5-20)$ & - & - & 0.188 \\
\hline CIS present [number $(\%)]$ & $5(31 \%)$ & $14(34 \%)$ & - & - & 1.00 \\
\hline
\end{tabular}

$P^{1}$ : a comparison between control group and cancer group (both BCG groups).

$P^{2}$ : a comparison between the BCG subgroups.

hence methylation analysis could not be performed. There was a BCG response in 41 patients and BCG failure in 16 patients (Table 4 ).

In NMDC high grade patients methylation was identified in WIF1, GATA4, TERT, BLC2, CDH13, RASSF1a, RASSF1b, TP73, CDKN2B, APC, TWIST1, PTEN,
SFRP1b. There was newly identified methylation in MUS81a, NTRK1 and PCCA.

Methylation status in CDKN2B $\left(P=0.00312^{* * *}\right)$ and MUS81a $\left(P=0.0191^{*}\right)$ is associated with the clinical outcomes of BCG instillation therapy response. CDKN2B and MUS81a unmethylation was found in BCG failure patients. 
Table 4. The presence of methylation of gene in the subgroups of patients.

\begin{tabular}{|c|c|c|c|c|c|c|}
\hline Gene & $\begin{array}{c}\text { BCG failure } \\
(\mathrm{n}=16)\end{array}$ & $\begin{array}{l}\text { BCG response } \\
(n=41)\end{array}$ & Cancer group & $\begin{array}{l}\text { Controls } \\
(n=13)\end{array}$ & $P^{1}$ & $P^{2}$ \\
\hline TIMP3 & $3(19 \%)$ & $6(15 \%)$ & $9(16 \%)$ & $0(0 \%)$ & 0.189 & 0.710 \\
\hline APC & $7(44 \%)$ & $14(34 \%)$ & $21(37 \%)$ & $0(0 \%)$ & $0.00635^{*}$ & 0.761 \\
\hline CDKN2A & $1(6 \%)$ & $1(2 \%)$ & $2(4 \%)$ & $0(0 \%)$ & 1.00 & 0.501 \\
\hline MLH1a & $3(19 \%)$ & $6(15 \%)$ & $9(16 \%)$ & $0(0 \%)$ & 0.189 & 0.710 \\
\hline ATM & $1(6 \%)$ & $1(2 \%)$ & $2(4 \%)$ & $0(0 \%)$ & 1.00 & 0.501 \\
\hline RARB & $1(6 \%)$ & $5(12 \%)$ & $6(11 \%)$ & $0(0 \%)$ & 0.587 & 0.659 \\
\hline CDKN2B & $2(13 \%)$ & $22(54 \%)$ & $24(42 \%)$ & $1(9 \%)$ & $0.0229^{*}$ & $0.00312^{* *}$ \\
\hline $\mathrm{HIC} 1$ & $1(7 \%)$ & $2(4 \%)$ & $3(5 \%)$ & $0(0 \%)$ & 1.00 & 1.00 \\
\hline CHFR & $0(0 \%)$ & $0(0 \%)$ & $0(0 \%)$ & $0(0 \%)$ & - & - \\
\hline BRCA1 & $0(0 \%)$ & $0(0 \%)$ & $0(0 \%)$ & $0(0 \%)$ & - & - \\
\hline CASP8 & $1(6 \%)$ & $0(0 \%)$ & $1(2 \%)$ & $0(0 \%)$ & 1.00 & 0.291 \\
\hline CDKN1B & $0(0 \%)$ & $0(0 \%)$ & $0(0 \%)$ & $0(0 \%)$ & - & - \\
\hline KLLN & $1(6 \%)$ & $2(4 \%)$ & $3(5 \%)$ & $0(0 \%)$ & 1.00 & 1.00 \\
\hline BRCA2 & $0(0 \%)$ & $0(0 \%)$ & $0(0 \%)$ & $0(0 \%)$ & - & - \\
\hline CD44 & $3(19 \%)$ & $3(7 \%)$ & $6(11 \%)$ & $0(0 \%)$ & 0.587 & 0.342 \\
\hline RASSF1a & $8(50 \%)$ & $15(37 \%)$ & $23(40 \%)$ & $0(0 \%)$ & $0.00289^{* *}$ & 0.550 \\
\hline DAPK1 & $1(6 \%)$ & $2(4 \%)$ & $3(5 \%)$ & $0(0 \%)$ & 1.00 & 1.00 \\
\hline VHL & $0(0 \%)$ & $0(0 \%)$ & $0(0 \%)$ & $0(0 \%)$ & - & - \\
\hline ESR1 & $2(13 \%)$ & $6(15 \%)$ & $8(14 \%)$ & $0(0 \%)$ & 0.338 & 1.00 \\
\hline RASSF $1 b$ & $8(53 \%)$ & $18(44 \%)$ & $26(46 \%)$ & $0(0 \%)$ & $0.00104^{* *}$ & 1.00 \\
\hline TP73 & $6(33 \%)$ & $18(44 \%)$ & $24(42 \%)$ & $2(15 \%)$ & $0.0229^{*}$ & 0.765 \\
\hline FHIT & $0(0 \%)$ & $1(2 \%)$ & $1(2 \%)$ & $0(0 \%)$ & 1.00 & 1.00 \\
\hline CADM1 & $2(13 \%)$ & $4(10 \%)$ & $6(11 \%)$ & $0(0 \%)$ & 0.587 & 1.00 \\
\hline CDH13 & $13(81 \%)$ & $35(85 \%)$ & $48(84 \%)$ & $3(27 \%)$ & $0.00001^{* * *}$ & 0.402 \\
\hline GSTP1 & $1(6 \%)$ & $2(4 \%)$ & $3(5 \%)$ & $0(0 \%)$ & 1.00 & 1.00 \\
\hline MLH1b & $0(0 \%)$ & $0(0 \%)$ & $0(0 \%)$ & $0(0 \%)$ & - & - \\
\hline EPHB2 & $1(6 \%)$ & $0(0 \%)$ & $1(2 \%)$ & $0(0 \%)$ & 1.00 & 0.275 \\
\hline BCL2 & $11(69 \%)$ & $27(66 \%)$ & $38(67 \%)$ & $1(8 \%)$ & $0.00002^{* * *}$ & 1.00 \\
\hline PTEN & $4(27 \%)$ & $19(46 \%)$ & $23(40 \%)$ & $0(0 \%)$ & $0.00236^{* *}$ & 0.210 \\
\hline NF1a & $0(0 \%)$ & $0(0 \%)$ & $0(0 \%)$ & $0(0 \%)$ & - & - \\
\hline RARRES1 & $0(0 \%)$ & $7(17 \%)$ & $7(12 \%)$ & $0(0 \%)$ & 0.328 & 0.169 \\
\hline TERT & $14(88 \%)$ & $37(90 \%)$ & $51(89 \%)$ & $5(38 \%)$ & $<0.00001^{* * * *}$ & 1.00 \\
\hline THBS1 & $0(0 \%)$ & $0(0 \%)$ & $0(0 \%)$ & $0(0 \%)$ & - & - \\
\hline SFRP1a & $12(80 \%)$ & $36(88 \%)$ & $48(84 \%)$ & $10(91 \%)$ & 0.0925 & 0.179 \\
\hline IGF2R & $1(7 \%)$ & $3(6 \%)$ & $4(7 \%)$ & $0(0 \%)$ & 0.574 & 1.00 \\
\hline NF1b & $1(7 \%)$ & $6(15 \%)$ & $7(12 \%)$ & $0(0 \%)$ & 0.328 & 0.657 \\
\hline TWIST1 & $14(88 \%)$ & $37(90 \%)$ & $51(81 \%)$ & $9(69 \%)$ & $0.00113^{* *}$ & 1.00 \\
\hline APAF1a & $14(88 \%)$ & $35(85 \%)$ & $49(86 \%)$ & $11(85 \%)$ & 0.181 & 1.00 \\
\hline PCNA & $0(0 \%)$ & $0(0 \%)$ & $0(0 \%)$ & $0(0 \%)$ & - & - \\
\hline DNAJC 15 & $3(20 \%)$ & $15(37 \%)$ & $18(32 \%)$ & $8(73 \%)$ & 0.117 & 0.326 \\
\hline NTRK1 & $8(50 \%)$ & $19(46 \%)$ & $27(47 \%)$ & $1(9 \%)$ & $0.00396^{* *}$ & 0.762 \\
\hline PXMP4a & $2(13 \%)$ & $2(4 \%)$ & $4(7 \%)$ & $0(0 \%)$ & 0.574 & 0.300 \\
\hline MEN1a & $0(0 \%)$ & $0(0 \%)$ & $0(0 \%)$ & $0(0 \%)$ & - & - \\
\hline LMNA & $0(0 \%)$ & $0(0 \%)$ & $0(0 \%)$ & $0(0 \%)$ & - & - \\
\hline APAF1b & $1(7 \%)$ & $3(6 \%)$ & $4(7 \%)$ & $0(0 \%)$ & 0.574 & 1.00 \\
\hline PCCA & $4(26 \%)$ & $14(34 \%)$ & $18(32 \%)$ & $0(0 \%)$ & $0.0130^{*}$ & 0.744 \\
\hline PAX6 & $0(0 \%)$ & $0(0 \%)$ & $0(0 \%)$ & $0(0 \%)$ & - & - \\
\hline RBM14 & $0(0 \%)$ & $0(0 \%)$ & $0(0 \%)$ & $0(0 \%)$ & - & - \\
\hline MUS81a & $5(33 \%)$ & $28(68 \%)$ & $33(58 \%)$ & $0(0 \%)$ & $0.00002^{* * *}$ & $0.0191^{*}$ \\
\hline IGF2R & $0(0 \%)$ & $0(0 \%)$ & $0(0 \%)$ & $0(0 \%)$ & - & - \\
\hline SFRP1b & $6(40 \%)$ & $17(41 \%)$ & $23(40 \%)$ & $0(0 \%)$ & $0.00236^{* *}$ & 1.00 \\
\hline GATA4 & $12(75 \%)$ & $31(76 \%)$ & $43(75 \%)$ & $4(31 \%)$ & $0.00036^{* * *}$ & 1.00 \\
\hline PXMP4b & $2(13 \%)$ & $1(4 \%)$ & $3(5 \%)$ & $0(0 \%)$ & 1.00 & 0.179 \\
\hline MEN1b & $0(0 \%)$ & $0(0 \%)$ & $0(0 \%)$ & $0(0 \%)$ & - & - \\
\hline MUS81b & $1(7 \%)$ & $3(6 \%)$ & $4(7 \%)$ & $0(0 \%)$ & 0.574 & 1.00 \\
\hline WIF 1 & $7(47 \%)$ & $18(44 \%)$ & $15(44 \%)$ & $1(9 \%)$ & $0.00962^{*}$ & 1.00 \\
\hline
\end{tabular}

$P^{\mathrm{l}}$ : a comparison between control group and cancer group (both BCG groups).

$P^{2}$ : a comparison between the BCG subgroups.

Significance with Bonferroni modification: ${ }^{*} P<0.05,{ }^{* *} P<0.01,{ }^{* * *} P<0.001$ 


\section{DISCUSSION}

Our study results confirm the benefit of BCG instillation in patients with high grade NMIBC and CIS. BCG instillation is standard therapy for these patients. Metaanalyses have confirmed that BCG instillation after TUR is superior to TUR alone or TUR and chemotherapy ${ }^{11-14}$. $\mathrm{BCG}$ therapy reduces relative progression risk by about $27 \%$ (ref. ${ }^{15}$ ). Without any treatment, approximately $54 \%$ of patients with CIS progressed to muscle- invasive disease $^{4}$. Radical cystectomy is the sole radical procedure. BCG progression score in time TUR correlates with BCG failure in clinical practice. The outcome of the BCG progression score may have been affected by the small sample in our study. Toxicity and an optimal BCG schedule are limitations of BCG therapy. BCG intravesical treatment is associated with numerous side effects (cystitis, hematuria, prostatitis, epididymo-orchitis, arthralgia, fever, sepsis, allergic reactions)(ref. $\left.{ }^{16}\right)$. Serious side effects however are described in $<5 \%$ of patients ${ }^{17}$. The optimal BCG instillation schedule is unknown. The general consensus is 6-weekly induction of BCG instillation introduced by Morales $^{18}$, but the optimal number of inductions and the optimal frequency and duration of maintenance instillations remain unknown ${ }^{19}$. Although $\mathrm{BCG}$ has good clinical outcomes in general, we have many patients with BCG failure. This problematic group is the focus of our interest. Clinical markers for the prediction of BCG response or failure are missing. BCG failure patients spend a lot of time in conservative procedures and radical therapy is delayed. This could be fatal in terms of the patient's oncology prognosis ${ }^{20}$.

Studies have shown that methylation status plays an important role in carcinogenesis in various organs, including NMIBC (ref. ${ }^{21-30}$ ). Methylation status is a potent indicator for distinguishing patients responding to $\mathrm{BCG}$ from those who are failing to do so and who need the radical therapy approach ${ }^{31,32}$. We used the MS-MLPA probe sets ME001 and ME004 (MRC-Holland, Amsterdam, The Netherlands) selected by an experienced biochemist, suitable for identification of new typical bladder cancer methylation. These MS-MLPA sets have not been reported for predicting BCG response.

Hypermethylation of unmethylated $\mathrm{CpG}$ islands in the promoter regions of specific TSGs can be associated with both good and poor prognoses ${ }^{26-28,31,33}$. Hypomethylation (unmethylation, silent methylation) of specific TSGs also showed association with clinical outcomes ${ }^{30-32}$.

CDKN2B is cyclin-dependent kinase inhibitor 2B. This gene lies adjacent to the tumor suppressor gene CDKN2A in a region that is frequently mutated and deleted in a wide variety of tumors. This gene encodes a cyclin-dependent kinase inhibitor, which forms a complex with CDK4 or CDK6, and prevents the activation of the CDK kinases, and thus the encoded protein functions as a cell growth regulator that controls cell cycle $\mathrm{G} 1$ progression. The expression of this gene was found to be dramatically induced by TGF beta, which suggested its role in TGF beta-induced growth inhibition. Two alternatively spliced transcript variants of this gene, which encode distinct proteins, have been reported (provided by RefSeq, Jul 2008). Methylation of CDKN2B has been found in several cancer types including laryngeal squamous cell carcinoma, acute myeloid leukemia, and in ovarian cancer, where the presence of methylation in the CDKN2B gene was present mainly in clear cell carcinoma ${ }^{34-36}$.

MUS81 (Structure-Specific Endonuclease Subunit) is a protein coding gene. The MUS81 protein belongs to a conserved family of DNA structure-specific nucleases that play important roles in DNA replication and repair. Xing et al. 2015 demonstrated an essential role for the MUS81 nuclease in the maintenance of replication fork integrity ${ }^{37}$.

Unmethylation of $\mathrm{CpG}$ islands in CDKN2B especially and MUS81a TSGs is connected with BCG failure in our study. The mechanism by which unmethylation of CDKN2b and MUS81a favor the BCG failure is unknown.

The literature is sparse on data that predict of BCG response in the context of methylation status. Polyaminemodulated factor-1 (PMF-1) methylation status is described by Alvarez-Múgica as statistically relevant for prediction of BCG response in patients with high grade NMIBC (ref. ${ }^{32}$ ). Agundez published combination methylation statuses for TSGs MSH6 and THBS1 (MS-MLPA ME 002 probe set), with prediction of progression of high risk NMIBC after BCG instillation therapy ${ }^{31}$.

\section{CONCLUSION}

Genetic and epigenetic alterations play an important role in urothelial cancer pathogenesis. Deeper understanding of these processes could help us towards better diagnosis and management of this life threatening disease. Of epigenetic changes hypermethylation, hypomethylation and unmethylation are prospective research topics. According to our research results we can conclude that the methylation status of selected TSGs has the potential for predicting $\mathrm{BCG}$ response in patients with NMIBC high grade tumors, but cannot yet be safely relied on for common clinical application. TSGs such as PMF-1, MSH6, THBS1, CDKN2b and MUS81a are very promising for future research.

\section{Acknowledgement: Supported by MH CZ - DRO (UHHK, 00179906).}

We are grateful to staff of the Department of Biophysics and Biostatistics of Charles University Medical School in Hradec Kralove for their co-operation in the statistical data analysis.

The authors are grateful to native speaker of English Ian McColl MD, PhD for proof reading with the manuscript as well.

Author contributions: $\mathrm{PH}, \mathrm{MB}$ : manuscript writing; $\mathrm{PH}$, JP: data collection; MC: methylation analysis.

Conflict of interest statement: The authors state that there are no conflicts of interest regarding the publication of this article. 


\section{REFERENCES}

1. Ferlay J, Shin HR, Bray F, Forman D, Mathers C, Parkin DM. GLOBOCAN 2008 v1.2,Cancer Incidence and Mortality Worldwide: IARC CancerNase No. 10 2010, International Agency for Research on Cancer: Lyon, France.

2. Jemal A, Murray T, Ward E, Samuels A, Tiwari RC, Ghafoor A. Cancer statistics 2005. CA Cancer J Clin 2005;55(1):10-30.

3. Sylvester R, van der Meijden A, Witjes JA, Jakse G, Nomomura N Cheng $C$. High grade Ta urothelial carcinoma and carcinoma in situ of the bladder. Urology 2005;66(6 Suppl):90-107.

4. Lamm DL. Carcinoma in situ. Urol Clin North Am 1992;19(3):499-508.

5. Burger M, Catto JW, Dalbangi G, Grossman HD, Herr H, Karakiewicz P. Epidemiology and risk factors of urothelial bladder cancer. Eur Urol 2013;63(2):234-41.

6. Herr HW, Reuter VE. Progression of T1 bladder tumors. Cancer 1999;86(6):908-9.

7. Chmelarova M, Krepinska E, Spacek J, LacoJ, Beranek M, Palicka V Methylation in the p53 promoter in epithelial ovarian cancer. Clin Transl Oncol 2013;15(2):160-3.

8. Chmelarova M, Krepinka E, Spacek J, Laco J, Nekvindova J, Palicka Methylation analysis of tumour suppressor genes in ovarian cancer using MS-MLPA. Folia Biologica 2012,58(6):246-50.

9. Pavicic W, Perkiö E, Kaur S, Peltomäki P. Altered methylation at microRNA-associated CpG islands in hereditary and sporadic carcinomas: a methylation-specific multiplex ligation-dependent probe amplification (MS-MLPA)-based approach. Mol Med 2011;17(78):726-35.

10. Dvorakova E, Chmelarova M, Laco Jan, Palicka V, Spacek J. Methylation analysis of tumor suppressor genes in endometroid carcinoma of endometrium using MS-MPLA. Biomed Pap Med Fac Univ Palacky Olomouc Czech Repub 2013;157(4):298-303.

11. Malmström PU, Sylvester RJ, Crawford DE, Friedrich M, Krege S, Rintala H. An individual patient data meta-analysis of the long-term outcomes of ramdomised studies comparing intravecical mitomycin $C$ versus bacillus Calmette-Guérin for non-muscle- invasive bladder cancer. Eur Urol 2009;56(2):247-56.

12. Han RF, Pan JG. Can intravesical bacillus Calmette-Guérin reduce recurrence in patients with superficial bladder cancer? A meta-analysis of randomized trials. Urology 2006;67(6):1216-23.

13. Shelley MD, Wilt TJ, Court J, Coles J, Kynaston H, Mason MD. Intravesical bacillus Calmette- Guérin is superior to mitomycin $C$ in reducing tumour reccurence in high-risk superficial bladder cancer: a meta-analysis of randomized trials. BJU Int 2004;93(4):485-90.

14. Böhle A, Jocham D, Bock RP. Intravecical bacillus Calmette-Guérin versus mitomycin $C$ for superficial bladder cancer: a formal metaanalysis of comparative studies on reccurence and toxicity. J Urol 2003;169(1):90-5.

15. Sylvester RJ, van der Meijden AP, Lamm DL. Intravesical bacillus Calmette-Guérin reduces the risk of progression in patients with superficial bladder cancer: a meta-analysis of the published results of randomized trials. J Urol 2002;168:1964-70.

16. Chang PF, Kwong J, Wang ZP, Tian J, Jiang L, Yang K. Intravesical bacillus Calmette-Guérin versus epirubicin for Ta and T1 bladder cancer. Cochrane Database Syst Rev 2011;11(5).CD006885.

17. Van der Meijden AP, Sylvester RJ, Oosterlick W, HoeltI W, Bono AV. OERTC Genito-Urinary-Tract Cancer Group. Maintenance bacillus Calmette-Guérin for Ta, T1 bladder tumour is not associated with increased toxicity: results from a European Organisation for Research and Treatment of Cancer Genito-Urinary Group Phase III Trial. Eur Urol 2003;44(4):429-34.

18. Witjes JA, Paulo J, Soloway M, Lamm D, Kamat AM, Brausi M. Clinica practice recommedations for the prevention and management of intravesical therapy-associated adverse events. Eur Urol Suppl 2008;7(10):667-74.
19. Zlotta AR, van Vooren, JP, Huygen K, Drowart A, Decock M, Pirson M. What is the optimal regimen for BCG intravesical therapy? Are six weekly instillations necessary? Eur Urol 2000;37(4):470-7.

20. Kulkarni GS, Hakenberg OW, Gschwend JE, Thalmann G, Kassouf W, Kamat A. An updated critical analysis of the treatment strategy for newly diagnosed high-grade T1 (previously T1G3) bladder cancer. Eur Urol 2010;57(1):60-70.

21. Cabello MJ, Grau L, Franco N, Orenes E, Alvarez M, Blanca A. Multiplex Methylation Profile of Tumor Suppressor Gene in Bladder Cancer. J Mol Diagn 2011;13(1):29-40.

22. García-Baquero R, Puerta P, Betran M, Alvarez-Mújica M, AlvarezOssorio JL, Sánchez-Carbayo M. Methylation of tumor suppressor genes in a novel panel Predicts clinical outcomes in paraffin-embedded bladder tumors. Tumour Biol 2014;35(6):5777-86.

23. Ibragimova I, Dulaimi E, Slifker JM, Chen DY, Uzzo RG, Cairns P. A global profile of gene promoter methylation in treatment-naive urothelial cancer. Epigenetics 2014;9(5):760-73.

24. Salam C, Liang G, Tsai YC, Coulter J, Knowles MA, Feng AC. Progressive increase in de novo methylation of CpG islands in bladder cancer. Cancer Res 2000;60:2473-76.

25. Chan MW, Chan LW, Tang NL, Tong JH, Lo KW, Lee TL. Hypermethylation of multiple genes in tumor tissues and voided urine in urinary bladder cancer patients. Clin Cancer Res 2002;8:464-70.

26. Friedrich MG, Chandrasoma S, Siegmund KD, Weissenberger DJ, Cheng JC, Toma MI. Prognostic relevance of methylation markers in patients with non-muscle invasive bladder carcinoma. Eur J Cancer 2005;41:2769-78.

27. Dhawan D, Hamdy FC, Rehman I, Patterson J, Cross SS, Feeley KM. Evidence for the early onset of aberrant promoter methylation in urothelial carcinoma. J Pathol 2006;209:336-43.

28. Yates DR, Rehman I, Abbod MF, Meuth M, Cross SS, Linkens DA. Promotor hypermethylation identifies prognostic risk in bladder cancer. Clin Cancer Res 2007;13:2046-53.

29. Jarmalaite $S$, Jankevicius F, Kugonaite $K$, Suziedilis $K$, Mutanen $P$, Husgafvel-Pursiainen K. Promotor hypermethylation in tumor suppressor genes shows association with stage, grade and invasiveness of bladder cancer. Oncology 2008;75:145-51.

30. Wolff EM, Chihara Y, Pan F, Weisenberger DJ, Siegmund KD, Sugano K. Unique DNA methylation patterns distinguish noninvasive and invasive urothelial cancers and establish an epigenetic field defect in premalignant tissue. Cancer Res 2010;70:8169-78.

31. Agundez M, Grau L, Palou J, Algaba F, Villavicencio H, SánchezCarbayo M. Evaluation of the Methylation Status of Tumor Suppressor Genes for Predicting Bacillus Calmette-Guérin Response in Patients With T1G3 High-Risk Bladder Tumors. Eur Urol 2011;60:131-40.

32. Alvarez-Múgica M, Fernandez-Gomez JM, Cebrian V, Fresno F, Escaf S, Sánchez-Carbayo M. Polyamine- modulated Factor-1 Methylation Predicts Bacillus Calmette-Guérin Response in Patients with High-grade Non-muscle-invasive Bladder Carcinoma. Eur Urol 2013;63:364-70.

33. Maruyama R, Toyooka S, Toyooka KO, Virmani AK, Zochbaer-Müller $\mathrm{S}$, Farinas AJ. Aberrant promoter methylation profile of bladder cancer and its relationship to clinicopathological features. Cancer Res 2001;61:8656-63.

34. López F, Sampedro T, Lorente JL, Domínguez F, Hermsen M, Suáres C Utility of MS-MLPA in DNA methylation profiling in primary laryngeal squamous cell carcinoma. Oral Oncol 2014;50(4):291-7.

35. Jiang D, Hong Q, Shen Y, Xu Y, Zhu H, Li Y. The diagnostic value of DNA methylation in leukemia: a systematic review and meta-analysis. PLoS One 2014;9(5):e96822.

36. Ozdemir F, Altinisik J, Coksuer H, Buyru N. Methylation of tumor suppressor genes in ovarian cancer. Exp Ther Med 2012;4(6):1092-6.

37. Xing $M$, Wang X, Palmai-Pallag $T$, Shen $H$, Helleday T, Hickson ID. Acute MUS81 depletion leads to replication fork slowing and a constitutive DNA damage response. Oncotarget 2015;6(35):37638-46. 